\title{
Correction to: A novel series of mixed-ligand M(II) complexes containing 2,2'-bipyridyl as potent a-glucosidase inhibitor: synthesis, crystal structure, DFT calculations, and molecular docking
}

\author{
Davut Avcı ${ }^{1}$ Sümeyye Altürk ${ }^{1} \cdot$ Fatih Sönmez $^{2} \cdot$ Ömer Tamer $^{1} \cdot$ Adil Başoğlu $^{1} \cdot$ Yusuf Atalay $^{1} \cdot$ Belma Zengin Kurt $^{3}$. \\ Necmi Dege ${ }^{4}$
}

Published online: 14 July 2021

(c) Society for Biological Inorganic Chemistry (SBIC) 2021

\section{Correction to: \\ JBIC Journal of Biological Inorganic Chemistry (2019) 24:747-764 \\ https://doi.org/10.1007/s00775-019-01688-9}

The authors regret that the project number was incorrectly given in the article.

The authors would like to apologize for any inconvenience caused.

The corrected part is given as follows:

\section{Acknowledgements}

This work was supported by the Scientific and Technological Research Council of Turkey (TÜBITAK) (Project Number: MFAG-117F234).

Publisher's Note Springer Nature remains neutral with regard to jurisdictional claims in published maps and institutional affiliations.

The original article can be found online at https://doi.org/10.1007/ s00775-019-01688-9.

Davut Avc1

davci@sakarya.edu.tr

1 Department of Physics, Faculty of Arts and Sciences, Sakarya University, 54187 Sakarya, Turkey

2 Pamukova Vocational School, Sakarya University of Applied Sciences, 54055 Sakarya, Turkey

3 Department of Pharmaceutical Chemistry, Faculty of Pharmacy, Bezmialem Vakif University, 34093 Istanbul, Turkey

4 Department of Physics, Faculty of Arts and Sciences, Ondokuz Mayıs University, 55139 Samsun, Turkey 